\title{
Contaminación bacteriana de esponja de lavado y bachas de cocina de Cantinas de Escuelas de Asunción y Gran Asunción
}

\author{
Bacterial contamination of Sponges used for Washing and \\ Kitchen Sinks in School Cafeterias in Asunción and Greater \\ Asunción area Schools
}

\author{
Noemí Zárate ${ }^{1}$, Clyde Cowan, Christian Román, Gonzalo Lombardo
}

\section{RESUMEN}

Introducción: Las esponjas y el fregadero constituyen un medio favorable para el crecimiento de microorganismos. Objetivo: Evaluar la presencia de microorganismos en esponjas de lavado y bachas de cocina de cantinas de escuelas y colegios de Asunción y gran Asunción. Materiales y Métodos: estudio fue observacional descriptivo de corte transversal. Se tomó muestras de esponjas de lavado e hisopado de bachas de cocina de 25 cantinas de escuelas y colegios públicos y privados de Asunción y gran Asunción. Se utilizo medios de cultivo para bacterias aerobias mesófilas y coliformes fecales, Staphylococcus aureus y Salmonella spp. Se considero contaminación la presencia de $\geq 100$ UFC para las bacterias aerobias mesófilas y cualquier crecimiento de bacterias patógenas. El análisis se realizó en Micorsoft Excell utilizando estadísticas descriptivas. Resultados: Fueron incluidas 11 instituciones privadas y 14 públicas. El 88\% (22/25 de las esponjas presentaron alta contaminación con bacterias aerobias mesófilas; 20 (80\%) con coliformes fecales y 1 (4\%) estéril. Hisopados de bachas, 21 (84\%) presentaron alta contaminación las mesófilas y 20 (80\%) con coliformes fecales, 1 (4\%). No se aisló Salmonella spp. ni Staphylococcus aureus. No hubo diferencias en la contaminación de bachas entre instituciones públicas o privadas, pero si en las esponjas $14 / 14$ vs $6 / 11$ en las públicas y privadas respectivamente $\mathrm{p}=0.008$ (T Fisher). Conclusión: esponjas de cocina y las bachas de las escuelas de Asunción y gran Asunción estudiadas, presentaron alto porcentaje de contaminación bacteriana tanto con bacterias aerobias mesófilas como con
ABSTRACT

Introduction: Sponges and the sink are a favorable medium for microorganism growth. Objective: To evaluate the presence of microorganisms in washing sponges and kitchen sinks in school cafeterias in Asunción and Greater Asunción. Materials and Methods: This was a descriptive, observational and cross-sectional study. Samples were taken by swabbing from washing sponges and kitchen sinks from 25 public and private school cafeterias in Asunción and the Greater Asunción area. Culture media were used for aerobic mesophilic and fecal coliform bacteria, Staphylococcus aureus and Salmonella species. The presence of $\geq 100 \mathrm{CFU}$ for mesophilic aerobic bacteria and any growth of pathogenic bacteria was considered contamination. The analysis was performed with Microsoft Excel using descriptive statistics. Results: 11 private and 14 public institutions were included. $88 \%$ (22/25 of the sponges presented high contamination with aerobic mesophilic bacteria; $20(80 \%)$ with fecal coliforms and $1(4 \%)$ was sterile. Sink swabs: 21 (84\%) presented high contamination with mesophylls and 20 (80\%) with fecal coliforms, 1 (4\%) was sterile. No Salmonella species or Staphylococcus aureus was isolated. There were no differences in the contamination of sinks between public or private institutions, but in sponges, $14 / 14$ (public) were contaminated vs $6 / 11$ (private), $p=0.008$ (T Fisher). Conclusions: kitchen sponges and sinks from the schools of Asuncion and Greater Asuncion area in this study presented a high percentage of bacterial contamination with both aerobic mesophilic bacteria and fecal coliforms. No Staphylococcus aureus or Salmonella species were isolated.

\footnotetext{
${ }^{1}$ Universidad del Norte. Facultad de Ciencias Biomédicas. Carrera Nutrición. Asunción, Paraguay.

Correspondencia: Noemí Zárate Correo: minozaa60@hotmail.com

Conflicto de interés: Los autores declaran no poseer conflicto de interés.

Recibido:24/06/2020 Aceptado:06/07/2020

Doi: https://doi.org/10.31698/ped.47022020010
} 
coliformes fecales. No se aisló Staphylococcus aureus ni Salmonella spp.

Palabras claves: Contaminación, enfermedades transmitidas por alimentos, bacterias, alimentos, transmisión.

\section{INTRODUCCIÓN}

La limpieza es primordial para evitar la propagación de microorganismos patógenos en la cocina, sobre todo en determinadas zonas como el fregadero, encimera o tablas de picar y esponjas de lavado. Las esponjas y los estropajos utilizados en la cocina para labores de limpieza pueden producir el efecto contrario si no se utilizan de manera adecuada ${ }^{(1)}$.

Las condiciones de humedad y los restos de comida que se almacenan en las grietas de estos utensilios constituyen un medio favorable para el crecimiento de microorganismos como bacterias y hongos, algunos nocivos para la salud, aunque con unas pautas sencillas se pueden evitar los riesgos ${ }^{(1)}$. El fregadero de la cocina puede estar 100.000 veces más contaminado que el lavabo del baño por su frecuente contacto con la comida ${ }^{(2)}$ y puede convertirse en un gran foco de infección que contamine el resto de la cocina y los alimentos que en ella se preparan; es fundamental mantenerlo limpio ${ }^{(3)}$.

Es importante distinguir entre "limpiar" e "higienizar". El primero se refiere al proceso de remoción física de la suciedad y los restos de comida. En cambio "higienizar" consiste en desinfectar o matar los gérmenes ${ }^{(4)}$.

Los trapos, paños y otros utensilios de limpieza tienen que mantenerse limpios y cambiarse diariamente. No se recomienda el uso de esponjas, por su alto grado de contaminante. Se recomienda el uso de paños distintos para lavar los platos y las superficies con el fin de prevenir la propagación de los microorganismos ${ }^{(5)}$.

La OMS promueve la disponibilidad de alimentos inocuos, sanos y saludables para toda la población, a fin de garantizar la seguridad alimentaria. También
Key words: Contamination, foodborne illness, bacteria, foods, transmission.

se afana en promover la integración de la inocuidad de los alimentos a través de programas de nutrición y seguridad alimentaria ${ }^{(6)}$.

Según la OMS los alimentos insalubres están relacionados con la muerte de unos 2 millones de personas al año, en su mayoría niños. Los alimentos que contienen bacterias, virus, parásitos o sustancias químicas nocivas causan más de 200 enfermedades, que van desde la diarrea hasta el cáncer ${ }^{(7)}$. Estas cifras mundiales revelan, cuanto menos, la fragilidad de los programas de protección de alimentos para prevenir y controlar estas enfermedades ${ }^{(8)}$.

En el Paraguay la implementación de las técnicas de buenas prácticas higiénicas en la elaboración de alimentos es poco aplicada y no está suficientemente controlada ${ }^{(9)}$.

El objetivo del presente estudio fue determinar la presencia de microorganismos en esponjas de lavado y bachas de cocina de cantinas de escuelas y colegios de Asunción y gran Asunción en el periodo de noviembre de 2016 y mayo 2019.

\section{MATERIALES Y MÉTODOS}

\section{Lugar del estudio}

Se realizó un estudio observacional descriptivo de corte transversal. Por un muestreo no probabilístico de conveniencia fueron incluidas escuelas y colegios (educación primaria y secundaria) de Asunción y gran Asunción que poseían cantinas con cocinas que elaboraban los alimentos, que aceptaron participar del estudio. Las unidades de estudio fueron las esponjas utilizadas en la cocina para lavar los utensilios y el hisopado de las bachas de la cocina. 


\section{Técnica del laboratorio}

Las muestras fueron tomadas en las instituciones educativas según criterio de inclusión en día y hora no agendada para evitar que las zonas de toma de muestras se encuentren alteradas.

Se toma muestras de las esponjas de cocina que se hallaban en uso en ese momento con una pinza estéril y se introdujo en un frasco conteniendo $200 \mathrm{ml}$ de agua peptona, correctamente rotulado identificando. $\mathrm{Al}$ mismo tiempo se realiza un hisopado de $30 \mathrm{~cm}$ de superficie alrededor del orifico de desagüe de la bacha de la cocina que también se encentraba en uso, con un hisopo de algodón estéril, el cual se introdujo en un tubo con medio de transporte Agar Cary Blair también correctamente identificado.

Las muestras tomadas fueron llevadas refrigeras al Servicio de Bacteriología del Hospital Central de Policía "Rigoberto Caballero" en donde se procedió a realizar el estudio bacteriológico de las muestras.

Del agua peptona de los frascos conteniendo las esponjas se realizó diluciones de 1:10, 1:100, 1:1000 con agua peptona estéril y las tres diluciones de cada muestra fueron sembradas en placas de Plate count ágar y Agar Mc Conkey colocando 0,1 ml de cada dilución distribuyendo ese volumen sobre toda la placa (sembrado por extensión) con una pipeta de Drigalski. Las placas sembradas fueron llevadas a la estufa de cultivo a $35{ }^{\circ} \mathrm{C}$ por $24 \mathrm{Hs}$. Esto para el recuento de bacterias aerobias mesófilas (BAM) y coliformes fecales.

Por otro lado, con un ansa bacteriológica (levanta 10 microlitros de líquido) fue sembrado directamente el agua peptona conteniendo las esponjas en Agar manitol para la búsqueda de Staphylococcus aureus y en Agar S.S. para la búsqueda de Salmonella. Estas placas fueron también incubadas en estufa de cultivo a $35^{\circ} \mathrm{C}$ por $24 \mathrm{Hs}$.

Transcurrido este tiempo se procedió al recuento bacteriano teniendo en cuenta la dilución más alta para calcular el recuento en UFC/ml Unidades Formadoras de Colonias/ml.

En el agar manitol se buscaron colonias amarillas compatibles con Staphylococcus aureus, realizando posteriormente pruebas bioquímicas y serológicas para su confirmación.

En el agar SS se buscaron colonias negras con sulfhídrico sospechosas de Salmonella realizando luego pruebas bioquímicas y serológicas para su confirmación.

Las muestras de los hisopados de bachas también se sembraron en los mismos medios, incubadas y se realizó el recuento bacteriano también en U.F.C./ml

\section{Variables y conceptualización}

Recuento de Bacterias Aerobias Mesófilas (BAM) en esponjas de lavados y bachas de cocina: Se midió en (UFC/ml) Unidades formadoras de Colonias por ml; teniendo en cuenta que el valor normal es de hasta $100 \mathrm{UFC} / \mathrm{ml}$.

Recuento de Coliformes fecales en esponjas de lavados y bachas de cocina: Se midió en (UFC/ml) Unidades formadoras de Colonias por ml; teniendo en cuenta que el valor normal es NEGATIVO, es decir cero UFC/ml.

Recuento de Bacterias Patógenas (Salmonella y Staphylococcus aureus) en esponjas de lavados y bachas de cocina: Se midió en (UFC/ml) Unidades formadoras de Colonias por $\mathrm{ml}$; teniendo en cuenta que el valor normal es NEGATIVO es decir cero UFC/ml.

\section{Análisis de los datos}

Los resultados fueron consignados en una planilla Microsoft Office Excel ${ }^{\circledR}$ 2010. Para el análisis se utilizó estadísticas descriptivas. En el análisis se discrimino a las escuelas dependientes del estado como "Escuelas Públicas" y las privadas como “Escuelas Privadas", se elaboró tablas de distribución de frecuencias para la variable dicotómica y para las cualitativas ordinales. Una vez digitalizada y comprobada la base de datos; se procedió al análisis de datos obtenidos. La sección descriptiva de resultados se expresó en: promedio y desviaciones estándar (DE) en el caso de variables cuantitativas y para las variables cualitativas se utilizó frecuencia (n) y porcentaje (\%). La comparación entre instituciones 
públicas y privadas se realizó utilizando el test exacto de Fisher.

\section{RESULTADOS}

Durante el periodo de estudio fueron incluidas 25 Escuelas, 14/25 fueron públicas y 11/25 privadas. Se analizaron 25 esponjas de cocina y 25 hisopados de bachas.

Los resultados obtenidos en el estudio bacteriológico de muestras de esponjas para las bacterias aerobias mesófilas (BAM) y para coliformes fecales puede verse en la Tabla 1.

Tabla 1. Recuento de Bacterias Aerobias Mesófilas y Coliformes fecales en Esponjas de Lavado.

\begin{tabular}{lcc}
\hline U.F.C. BAM* & $\mathbf{n}$ & $\mathbf{\%}$ \\
\hline 0 & 1 & 4 \\
90 & 1 & 4 \\
90000 & 1 & 4 \\
$>100.000$ & 22 & 88 \\
\hline U.F.C. coliformes fecales & $\mathbf{n}$ & $\mathbf{\%}$ \\
\hline 0 & 1 & 4 \\
60 & 1 & 4 \\
60000 & 1 & 4 \\
70000 & 1 & 4 \\
80000 & 1 & 4 \\
$>100.000$ & 20 & 80 \\
\hline Total, de muestras & $\mathbf{2 5}$ & $\mathbf{1 0 0}$ \\
\hline *U.F.C.BAM: Unidades Formadoras de Colonias Bacterias Aerobias Mesófilas
\end{tabular}

No se aisló Salmonella spp. ni Staphylococcus aureus.

Los resultados obtenidos en el estudio bacteriológico de muestras de bachas de cocina de las 25 escuelas y colegios tanto para Bacterias Aerobias Mesófilas y Coliformes fecales puede observarse en la Tabla 2.

Tabla 2. Recuento de BAM y Coliformes fecales en Bachas de Cocina.

\begin{tabular}{lcc}
\hline U.F.C. BAM ${ }^{*}$ & $\mathbf{n}$ & $\mathbf{\%}$ \\
\hline 0 & 1 & 4 \\
80 & 1 & 4 \\
110 & 1 & 4 \\
$>10.000$ & 1 & 4 \\
$>100.000$ & 21 & 84 \\
\hline U. F.C. Coliformes fecales & $\mathbf{n}$ & $\%$ \\
\hline 0 & 1 & 4 \\
20 & 1 & 4 \\
70 & 1 & 4 \\
90000 & 1 & 4 \\
$>10.000$ & 1 & 4 \\
$>100.000$ & 20 & 80 \\
\hline Total de muestras & $\mathbf{2}$ & $\mathbf{1 0 0}$ \\
\hline *U.F.C.BAM: Unidades Formadoras de Colonias Bacterias Aerobias Mesófilas
\end{tabular}

No se aisló Salmonella spp. ni Staphylococcus aureus.

Se realizó la comparación de los resultados obtenidos tanto del cultivo de las esponjas como de las bachas de cocina entre las escuelas, de acuerdo al carácter de privadas o públicas. (Tabla 3 y 4 ).

Tabla 3. Comparación de contaminación bacteriana de los de Colegios y escuelas públicas y privadas de Rto Bacteriano en Esponjas de Lavados $\mathrm{N}=25$.

\begin{tabular}{lccccc}
\hline BAM * & \multicolumn{7}{c}{ PRIVADO $(\mathbf{n = 1 1})$} & \multicolumn{3}{c}{ PUBLICO $(\mathbf{n}=\mathbf{1 4})$} & \\
& $\mathbf{n}$ & $\mathbf{\%}$ & $\mathbf{n}$ & $\mathbf{\%}$ & $\mathbf{p}$ \\
\hline 0 & 1 & 9 & 0 & 9 & $0.07^{1}$ \\
90 & 1 & 9 & 0 & 9 & \\
90000 & 1 & 9 & 0 & 9 & \\
$>100.000$ & 8 & 73 & 14 & 73 & \\
\hline Coliformes fecales & $\mathbf{n}$ & $\mathbf{\%}$ & $\mathbf{n}$ & $\mathbf{\%}$ & $\mathbf{p}$ \\
\hline 0 & 1 & 9 & 0 & 0 & $0.008^{1}$ \\
60 & 1 & 9 & 0 & 0 & \\
60000 & 1 & 9 & 0 & 0 & \\
70000 & 1 & 9 & 0 & 0 & \\
80000 & 1 & 9 & 0 & 0 & \\
$>100.000$ & 6 & 55 & 14 & 100 & \\
\hline 'Test Exacto de Fisher & \multicolumn{5}{c}{}
\end{tabular}

Tabla 4. Comparación de la contaminación bacteriana de Colegios y escuelas públicas y privadas de Rto. Bacteriano en Bachas de Cocina.

\begin{tabular}{lccccc}
\hline BAM & $\begin{array}{c}\text { PRIVADO } \\
(\mathbf{n = 1 1 )}\end{array}$ & $\mathbf{\%}$ & $\begin{array}{c}\text { PUBLICO } \\
(\mathbf{n}=\mathbf{1 4})\end{array}$ & $\mathbf{\%}$ & $\mathbf{p}$ \\
\hline 0 & 1 & 9 & 0 & 0 & 0.28 \\
80 & & 0 & 1 & 7 & \\
110 & 1 & 9 & 0 & 0 & \\
$>10.000$ & 1 & 9 & 0 & 0 & \\
$>100.000$ & 8 & 73 & 13 & 93 & \\
\hline Coliformes & PRIVADO & & PUBLICO & & \\
\multicolumn{1}{c}{$(\mathbf{n}=\mathbf{1 1})$} & $\mathbf{\%}$ & $(\mathbf{n}=\mathbf{1 4})$ & $\mathbf{\%}$ & $\mathbf{p}$ \\
\hline 0 & 1 & 9 & 0 & 0 & 0.44 \\
20 & & 0 & 1 & 7 & \\
70 & 1 & 9 & & 0 & \\
90000 & & 0 & 1 & 7 & \\
$>10.000$ & 1 & 9 & & 0 & \\
$>100.000$ & 8 & 73 & 12 & 86 & \\
\hline
\end{tabular}

\section{DISCUSIÓN}

El estudio demostró un elevado porcentaje de contaminación bacteriana de las esponjas y bachas de la cocina de los colegios, tanto públicos como privados. Los resultados de contaminación bacteriana obtenidos en el estudio coinciden con otras publicaciones internacionales tales como los publicados por científicos de una Universidad 
alemana que tras secuenciar el ADN de las bacterias de 14 esponjas de cocinas usadas confirman que estas esponjas contienen cantidades ingentes de bacterias. De hecho, un sólo centímetro cúbico puede albergar una población de 50 mil millones de bacterias, una cifra que equivaldría siete veces la población de la Tierra. La mejor manera de asegurar una baja contaminación de esponjas de cocina es reemplazarlas una vez por semana ${ }^{(10)}$.

En EEUU se encontró 44\% de contaminación con coliformes fecales y Escherichia coli en el 15\% en implementos de cocina, entre ellos espongas de cocina de las casa de habitantes de una zona de Filadelfia ${ }^{(11)}$.

Aunque no se aisló en este estudio Salmonella spp. ni Staphylococcus aureus, la contaminación con coliformes fecales constituye una fuente de enfermedades gastrointestinales. El origen de la contaminación es la mala higiene de manipuladores y la mala práctica de manufactura (MPB) así como la contaminación cruzada con productos crudos. Varios de esos microorganismos están naturalmente presentes en el ambiente donde los alimentos se preparan y evidencian la falta de implementación y control de las técnicas de buenas prácticas higiénicas en la elaboración de alimentos. En estudios basados en simulación se demostró que las diferentes técnicas de lavado con detergentes y el secado disminuyen el contaje de gérmenes con potencialidad de producir enfermedades por consumo de alimentos contaminados ${ }^{(12)}$.

Cuando los coliformes llegan a los alimentos, no sólo sobreviven, sino que se multiplican. En productos alimenticios que han recibido un tratamiento térmico (pasteurización, horneado, cocción, etc.), se utilizan como indicadores de malas prácticas sanitarias. Los microorganismos coliformes constituyen un grupo heterogéneo con hábitat primordialmente intestinal para la mayoría de las especies que involucra. Escherichia coli que forma parte de los coliformes fecales (bacterias entéricas), existe como comensal en el intestino delgado de humanos y animales. Sin embargo, hay algunas cepas de E. coli patógenas que provocan enfermedades diarreicas. Este grupo de bacterias (diarreogénicas) se encuentra constituido por las siguientes cepas: E. coli enterotoxigénica (ETEC), E. coli enteropatógena (EPEC), E. coli enterohemorrágica (EHEC), E. coli enteroinvasiva (EIEC), E. coli enteroagregativa (EAEC) E. coli enteroadherente difusa (DAEC). Entre estas cepas EHEC produce una toxina que puede producir Síndrome Urémico Hemolítico (SUH) ${ }^{(13)}$.

Respecto a las Bacterias Aerobias Mesófilas (BAM), incluyen todos los microorganismos, capaces de desarrollar en presencia de oxígeno a una temperatura comprendida entre $20^{\circ} \mathrm{C}$ y $45^{\circ} \mathrm{C}$ con una óptima entre $30^{\circ} \mathrm{C}$ y $40^{\circ} \mathrm{C}$. Los recuentos de microorganismos en alimentos, con resultados altos, con frecuencia muestran la contaminación de materias primas o tratamientos no convenientes a partir de la perspectiva sanitaria. La existencia de una cantidad elevada de bacterias aerobias mesófilas que se desarrollan apropiadamente a temperatura corporal, significa que pueden existir las condiciones adecuadas para la proliferación de los microorganismos patógenos. Un recuento bajo de aerobios mesófilos no implica o no asegura la ausencia de patógenos o sus toxinas. No obstante, los datos obtenidos con relación a la patogenicidad de aquellas cepas son problemáticas, ya que determinadas cepas de bacterias aerobias mesófilas habituales, no comúnmente consideradas como causantes de las enfermedades transmitidas por alimentos, han sido indicadas como motivo de enfermedad ${ }^{(14)}$.

Sólo el hecho de aislar Coliformes Fecales demuestra una contaminación fecal y el 75\% de los trapos y esponjas están contaminados con esta familia de bacterias, que incluyen E. coli. de ahí que hay gran trabajo que hacer en concientizar y educar a la población en cuanto a prevención de ETAS así como la elaboración de manuales de buenas prácticas en la preparación de alimentos y el entrenamiento de los manipuladores de alimentos de estos locales, demostrando así la necesidad de una urgente acción de las instituciones y autoridades y sobre todo de la comunidad educativa en implementar las BPM (Buenas Prácticas de Manufactura) para evitar los elevados niveles de contaminación bacteriana. 


\section{CONCLUSIÓN}

La contaminación de las esponjas y bachas de la cocina de un grupo de escuelas y colegios de Asunción y gran Asunción fue muy elevada. Las causantes de la contaminación fueron bacterias aerobias mesófilas y coliformes fecales. No se

\section{REFERENCIAS}

1. Gómez D, Lavayén S, Nario F, Piquin A, Zotta C. Detección de microorganismos potencialmente patógenos en hogares de Mar Del Plata. Acta Bioquímica Clínica Latinoamericana[Internet]. 2011[citado 25 Nov 2019];45(3):2-6. Disponible en: http://www.redalyc.org/ pdf/535/53521520005.pdf

2. Ordoñez S, Duran M, Rosa T. Higiene alimentaria y su relación con la conservación, preparación y consumo de los alimentos en el orfanato Padre Julio Villarroel[Tesis]. Loja: Universidad de Loja; 2013[citado 25 Nov 2019]. Disponible en: http://dspace.unl.edu.ec/jspui/bitstream/123456789/16 268/1/tesis\%20publica\%20BIBLIOTECA.pdf

3. Azagra D. Las intoxicaciones alimentarias, un clásico del verano que se puede evitar [Internet]. Diario de Ibiza, Gastronómica; 2018[citado 25 Nov 2019]. Disponible en: https://mas.diariodeibiza.es/gastronomia/intoxicacionesalimentarias-clasico-del-verano-que-puede-evitar/

4. Maronna JC. Esponjas de cocina y trapos de cocina, lugar de encuentro de patógenos [Internet]. Secretaría de Calidad de Vida, Dirección de Seguridad e Higiene Alimentaria; 2010[citado el 15 Ene 2020]. Disponible en: https://www. consumer.es/seguridad-alimentaria/esponjas-de-cocina-yestropajos-lugar-de-encuentro-de-patogenos.html

5. Organización Mundial de la Salud. Manual sobre las cinco claves para la inocuidad de los alimentos [Internet]. Francia: OMS; 2007[citado el 16 Feb 2020]. Disponible en: http://www.who.int/foodsafety/publications/consumer/ manual_keys_es.pdf?ua=1

6. Organización Mundial de la Salud. Nutrición y seguridad alimentaria [Internet]. Ginebra: OMS; 2019[citado el 18 Feb 2020]. Disponible en: https://www. who.int/nutrition/publications/foodsecurity/state-foodsecurity-nutrition-2019/es/

7. Organización Mundial de la Salud. Día mundial de la salud 2015: inocuidad de los alimentos [Internet]. Ginebra: encontraron bacterias patógenas como Salmonella spp. ni Staphylococcus aureus.

Las instituciones públicas tuvieron un $100 \%$ de contaminación de las esponjas y bachas de la cocina, mientras que en las privadas resultó estéril esponja y bacha de cocina de una sola Institución.
OMS; 2015[citado el 18 Ene 2020]. Disponible en: https://www.who.int/campaigns/world-healthday/2015/event/es/

8. Organización Mundial de la Salud. Inocuidad de los alimentos [Internet]. Ginebra: OMS; 2020[citado el 18/01/2020]. Disponible en: https://www.who.int/es/ne ws-room/fact-sheets/detail/food-safety

9. Fernández N, Cabral de Bejarano S, Estigarribia G, Ortiz A, Ríos P. Condiciones higiénico-sanitarias basadas en las cinco claves de la OMS de los servicios de alimentación de hospitales del departamento de Caaguazú, Paraguay. Mem. Inst. Investig. Cienc. Salud. [Internet] 2018[citado el 05 Feb 2020];16(2):2-11. Disponible en: http://revistascienti ficas.una.py/index.php/RIIC/article/view/1361

10. Cardinale M, Kaiser D, Lueders T, Schnell S, Egert M. Microbiome analysis and confocal microscopy of used kitchen sponges reveal massive colonization by Acinetobacter, Moraxella and Chryseobacterium species. Sci Rep. 2017;7(1):5791. doi: https://doi.org/10.1038/s415 98-017-06055-9

11. Borusso PA, Quinlan JJ. Prevalence of Pathogens and Indicator Organisms in Home Kitchens and Correlation with Unsafe Food Handling Practices and Conditions. J Food Prot. 2017;80(4):590-597. doi: https://doi.org/10.4315 /0362-028X.JFP-16-354

12. Rossvoll E, Langsrud S, Bloomfield S, Moen B, Heir E, Moretro T. The effects of different hygiene procedures in reducing bacterial contamination in a model domestic kitchen. J Appl Microbiol. 2015;119(2):582-593. doi: https://doi.org/10.1111/jam.12869

13. Camacho Cruz A, Giles Gómez M, Ortegón Ávila A, Palao Rincón M, Serrano López B, Velázquez Madrazo O. Técnicas para el Análisis Microbiológico de Alimentos. $2^{\mathrm{a}}$ ed. México: Facultad de Química, UNAM; 2009. 